\title{
Determinants of Neurological Functional Recovery Potential after Stroke in Young Adults
}

\author{
Daniel Haselbach Anastasia Renggli Stefano Carda \\ Alexandre Croquelois \\ Neurorehabilitation Unit, Department of Clinical Neurosciences, \\ Lausanne University Hospital, University of Lausanne, Lausanne, Switzerland
}

Key Words

Stroke $\cdot$ Stroke recovery $\cdot$ Functional Independence Measure

\section{Abstract}

Background/Objectives: Despite recent progress in stroke prevention and acute treatment, neurorehabilitation remains one of the main methods of treatment in the management of stroke patients. The aim of this study is to point out some important predicting factors of inhospital neurorehabilitation outcomes. Methods: A rehabilitation registry including all patients who had undergone a standardized program of neurorehabilitation at the neurorehabilitation unit of the Lausanne University Hospital, Lausanne, Switzerland, was created. Patients aged $<65$ years and having experienced a first ever nontraumatic stroke from 2005 to 2010 were admitted. Using logistical regression models, predicting factors for each patient were compared to the exit Functional Independence Measure (FIM) score. Results: Age $>55$ years, gender, aphasia, hemilateral spatial neglect, spasticity, complications, length of stay $>70$ days, entry FIM $>100$ and relative possible FIM gain/week of $>10 \%$ were considered to be significant and independent predicting factors of the neurorehabilitation outcome. Discussion/Conclusion: Some factors of the in-hospital rehabilitation period have been identified before (spasticity, complications, length of stay, relative possible FIM gain/week) and should be considered for a better management of the neurorehabilitation therapy. In addition, a personalized rehabilitation strategy based on the patient's individual needs should be aimed at. The question of resource allocation can also be addressed with regard to the present findings. 


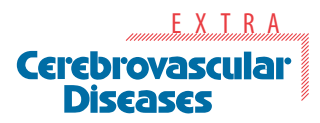

\begin{tabular}{l|l}
\hline \multicolumn{2}{l}{ Cerebrovasc Dis Extra 2014;4:77-83 } \\
\hline DOI: $10.1159 / 000360218$ & $\begin{array}{l}\text { C 2014 S. Karger AG, Basel } \\
\text { www.karger.com/cee }\end{array}$ \\
\hline Haselbach et al.: Determinants of Neurological Functional Recovery Potential after
\end{tabular}

Haselbach et al.: Determin
Stroke in Young Adults

\section{Introduction}

In the Western countries, stroke is the third leading cause of death, the second cause of dementia and the first leading cause of disability in adults [1]. In Switzerland, the incidence is about 200 cases per 100,000 patients per year, about half of them survive with a relatively severe disability [2]. In Western countries, it has been shown that total long-term costs of a stroke patient can rise up to EUR 228,038 [3]. The high prevalence of stroke and the high direct and indirect costs it generates make the management of stroke patients a national healthcare priority. Despite the progress made in the acute management of stroke patients, neurorehabilitation remains the main method of treatment in the management of stroke patients with neurological deficits. Moreover, the prevalence of risk factors for stroke is expected to rise - as is the survival of stroke patients. A recent study has also shown a trend towards increasing stroke incidence at younger ages (age 20-54 years) during the past decade [4]. The result is an increased number of stroke patients. Furthermore, the rise in neurorehabilitation needs takes place in a context where available resources are limited.

The intensity effect between multiprofessional treatment and deficit recovery for neurorehabilitation patients is proven [5]. Our center guidelines recommend 7-10 treatments per week per therapist as the gold standard regarding the management of moderate-to-severe neurological deficit in young patients. Moreover, the rehabilitation program (intensive in-hospital rehabilitation vs. early supported home discharge) should be different between young active patients and older retired patients regarding needs and goals. Therefore, these two groups should also be studied separately. Even though there are some factors known to be of bad prognosis in rehabilitation such as age [6], severity of stroke, bad recovery after 3 months [7], aphasia [8], unilateral spatial neglect [9], very little is known about how these factors influence functional recovery during in-hospital rehabilitation. No quantifiable assessment and no clinical recovery prediction can be made on this basis. The actual literature consists mainly of retrospective studies [10] without patient stratification and inhomogeneous data [11-13].

The purpose of this study is to point out acute and chronic factors that affect the functional recovery of stroke patients admitted in a high-intensity rehabilitation program and quantify their recovery potential. This will help to plan an appropriate setting for stroke patient rehabilitation programs and provide information on the outcome at an early standpoint, and thus improve the efficiency of rehabilitation units as well as permit a better patients flow coordination.

\section{Methods}

Our research consisted of a prospective study including all patients who benefited from an intensive neurorehabilitation treatment with the same rehabilitation team between 2005 and 2010 after a first-ever nontraumatic stroke, and meeting the inclusion criteria described below. It is noteworthy that all included data were routinely acquired in our unit for statistical purpose, and the present study required no additional data exclusively dedicated to the analysis above. The present study has been approved by our local ethical committee (Commission cantonale (VD) d'éthique de la recherche sur l'être humain, Lausanne, Switzerland).

The population of this study was a selected population as all patients were $<65$ years of age. Regarding the rehabilitation intensity, patients $>65$ years of age were considered unable to undergo the program and were addressed to other rehabilitation centers. Furthermore, the rehabilitation potential between young and old patients could vary and mixing both popula- 
tions could have a bias effect on the statistical results. This affects the mean age of our population, which is almost 15 years younger than in most previous studies [14]. The neurorehabilitation unit of the Lausanne University Hospital, Lausanne, Switzerland, admits approximately 130 new patients each year. About 55 of them suffered from stroke and about 35 met our inclusion criteria. These criteria were: first ever nontraumatic ischemic or hemorrhagic stroke, age $>65$ years, no severe comorbidity such as malignant tumor or a known physical handicap from other etiology, no occurrence of severe complications requiring long-term transfer to another unit and thus interfering with an adequate neurorehabilitation treatment.

A stroke rehabilitation registry containing the following items was created: age, sex, presence of known cardiovascular risk factors [CVRFs; hypertension (HBP), diabetes (DM), cigarette smoking (CS), hypercholesterolemia (HC)], presence of other coronary heart disease, other cardiac affection, treatment at time of stroke, stroke etiology (according to the TOAST classification), stroke type (ischemic vs. hemorrhagic), symptoms after stroke (motor, sensitive, visual, aphasia, unilateral spatial neglect), location (right, left, both), treatment in the acute phase, time interval between stroke onset and rehabilitation admission (OAI), occurrence of pain, spasticity, depression and complications (infection, stroke recurrence, etc.) during rehabilitation and length of stay (LoS). The Functional Independence Measure (FIM) entry and exit scores of all patients were also included.

The registry also contained the FIM delta score (exit FIM-entry FIM), the FIM delta score related to $\operatorname{LoS}(\Delta$ score/LoS), and the relative possible FIM gain/week ( $\Delta$ entry-exit scores/ 126-entry FIM/week) which is the percentage of potential FIM points gained per week of rehabilitation, and thus reflecting recovery velocity.

In a previous study [15], patients that could be discharged home had a median FIM of 108.5. In our opinion, a home discharge is not a relevant item for neurological recovery, as it is biased by the fact that it is strongly dependent on the patient's social situation and family surrounding [16]. Therefore, in the present study, we considered that a FIM of $>115$ allows autonomy in everyday life (basic and instrumental activities of daily living) independent of any familial and social assistance.

Statistical analysis was carried out using SPSS package (version 19.0, IBM). The $\chi^{2}$ test was used for frequency comparisons. Then, relation analysis between variables was performed with a binomial logistical regression model. The limit of significance was set at $\mathrm{p}=0.05$ for all tests.

\section{Results}

A total of 172 patients were eligible for the study; demographic and clinical characteristics are described in table 1. Univariate analysis shows the following results with an FIM exit score of $>115$ :

Factors present before admission: age $<55$ years $(p=0.026)$, gender $(p=0.070)$, HBP $(\mathrm{p}=0.529), \mathrm{DM}(\mathrm{p}=0.829), \mathrm{HC}(\mathrm{p}=0.637), \mathrm{CS}(\mathrm{p}=0.035)$, alcohol $(\mathrm{p}=1.0)$, coronary heart disease $(p=0.801)$, other cardiac diseases $(p=0.364)$, at least three cardiovascular risk factors $(p=0.186)$, depression before stroke $(p=0.402)$, stroke type (ischemic vs. hemorrhagic, $p=0.271)$, location $(p=0.334)$, aphasia $(p=0.053)$, unilateral spatial neglect $(p=$ 0.001 ), time from stroke onset to admission (OAI) ( $<$ or $>14$ days, $p=0.005$ ).

Factors present during rehabilitation: depression ( $<<0.001)$, pain $(\mathrm{p}<0.001)$, spasticity $(p<0.001)$, complications $(p<0.001)$, persistent HBP $(p=0.788)$, persistent DM $(p=0.260)$, psychotropic medication ( $p<0.001)$, duration $<70$ days $(p<0.001)$, FIM entry score $<100$ ( $p<0.001)$, and relative possible FIM gain/week of $<10 \%(\mathrm{p}<0.001)$. 


\section{Cerebrovascular \\ Diseases}

Table 1. Demographic and clinical characteristics

\begin{tabular}{l|l}
\hline Cerebrovasc Dis Extra 2014;4:77-83 \\
\hline DOI: 10.1159/000360218 & $\begin{array}{l}\text { c 2014 S. Karger AG, Basel } \\
\text { www.karger.com/cee }\end{array}$ \\
\hline
\end{tabular}

Haselbach et al.: Determinants of Neurological Functional Recovery Potential after Stroke in Young Adults

\begin{tabular}{|c|c|c|}
\hline & n (\%) & Mean \pm SD \\
\hline Subjects & 172 & \\
\hline Age & & $52 \pm 11$ \\
\hline Male & $110(64)$ & \\
\hline Female & $62(36)$ & \\
\hline \multicolumn{3}{|l|}{ Type } \\
\hline Ischemic & $130(76)$ & \\
\hline Hemorrhagic & $42(24)$ & \\
\hline \multicolumn{3}{|l|}{ Clinics } \\
\hline Aphasia & $69(40)$ & \\
\hline Unilateral spatial neglect & $59(34)$ & \\
\hline Pain & $63(37)$ & \\
\hline Depression & $51(30)$ & \\
\hline Spasticity & $21(12)$ & \\
\hline Complications & $49(29)$ & \\
\hline \multicolumn{3}{|l|}{ Location } \\
\hline Right & $59(34)$ & \\
\hline Left & $88(51)$ & \\
\hline Both & $25(15)$ & \\
\hline Entry FIM & & $93.6 \pm 28.4$ \\
\hline FIM $<100$ & $83(48)$ & \\
\hline FIM $>100$ & $89(52)$ & \\
\hline LoS & & $76.4 \pm 61.1$ \\
\hline$<70$ days & $99(58)$ & \\
\hline$>70$ days & $73(42)$ & \\
\hline OAI & & $20.0 \pm 17.8$ \\
\hline$<14$ days & $89(52)$ & \\
\hline$>14$ days & $83(58)$ & \\
\hline \multicolumn{3}{|c|}{ Relative possible FIM gain/week } \\
\hline$<10 \%$ & $114(66)$ & \\
\hline$>10 \%$ & $52(30)$ & \\
\hline Missing values & $6(4)$ & \\
\hline \multicolumn{3}{|l|}{ Discharge } \\
\hline Home & $166(97)$ & \\
\hline Others & $6(3)$ & \\
\hline
\end{tabular}

\begin{tabular}{llr}
\hline & $\begin{array}{l}\text { Odds ratio } \\
\text { (95\% confidence interval) }\end{array}$ & $\mathrm{p}$ value \\
\hline Age >55 years & $0.445(0.208-0.956)$ & 0.038 \\
Female gender & $0.401(0.187-0.859)$ & 0.019 \\
Aphasia & $0.369(0.167-0.816)$ & 0.014 \\
Unilateral spatial neglect & $0.216(0.096-0.486)$ & $<0.001$ \\
\hline
\end{tabular}

Table 2. Predicting factors existing before admission

All items with a p value of $<0.2$ on the univariate analysis were included in a multiple logistic regression model $(p=0.05)$; the results are shown in table 2 (factors present before admission) and table 3 (factors present during rehabilitation). These tables show which variables independently influence the potential of a patient to reach the FIM 115 mark during rehabilitation. 


\section{Cerebrovascular: \\ Diseases}

Table 3. Predicting factors during neurorehabilitation

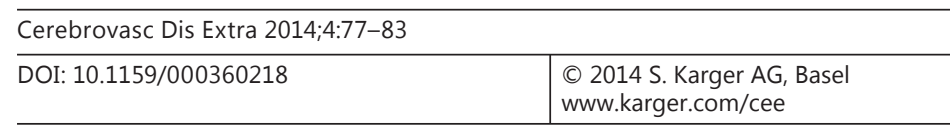

Haselbach et al.: Determinants of Neurological Functional Recovery Potential after Stroke in Young Adults

\begin{tabular}{lcr}
\hline & $\begin{array}{l}\text { Odds ratio } \\
\text { (95\% confidence interval) })\end{array}$ & p value \\
\hline Spasticity & $0.240(0.059-0.978)$ & 0.046 \\
Complications & $0.256(0.092-0.712)$ & 0.009 \\
LoS $>70$ days & $5.174(1.209-22.133)$ & 0.027 \\
Entry FIM $>100$ & $24.770(6.312-97.209)$ & $<0.001$ \\
Relative FIM gain/week $>10 \%$ & $15.401(2.866-82.771)$ & 0.001 \\
\hline
\end{tabular}

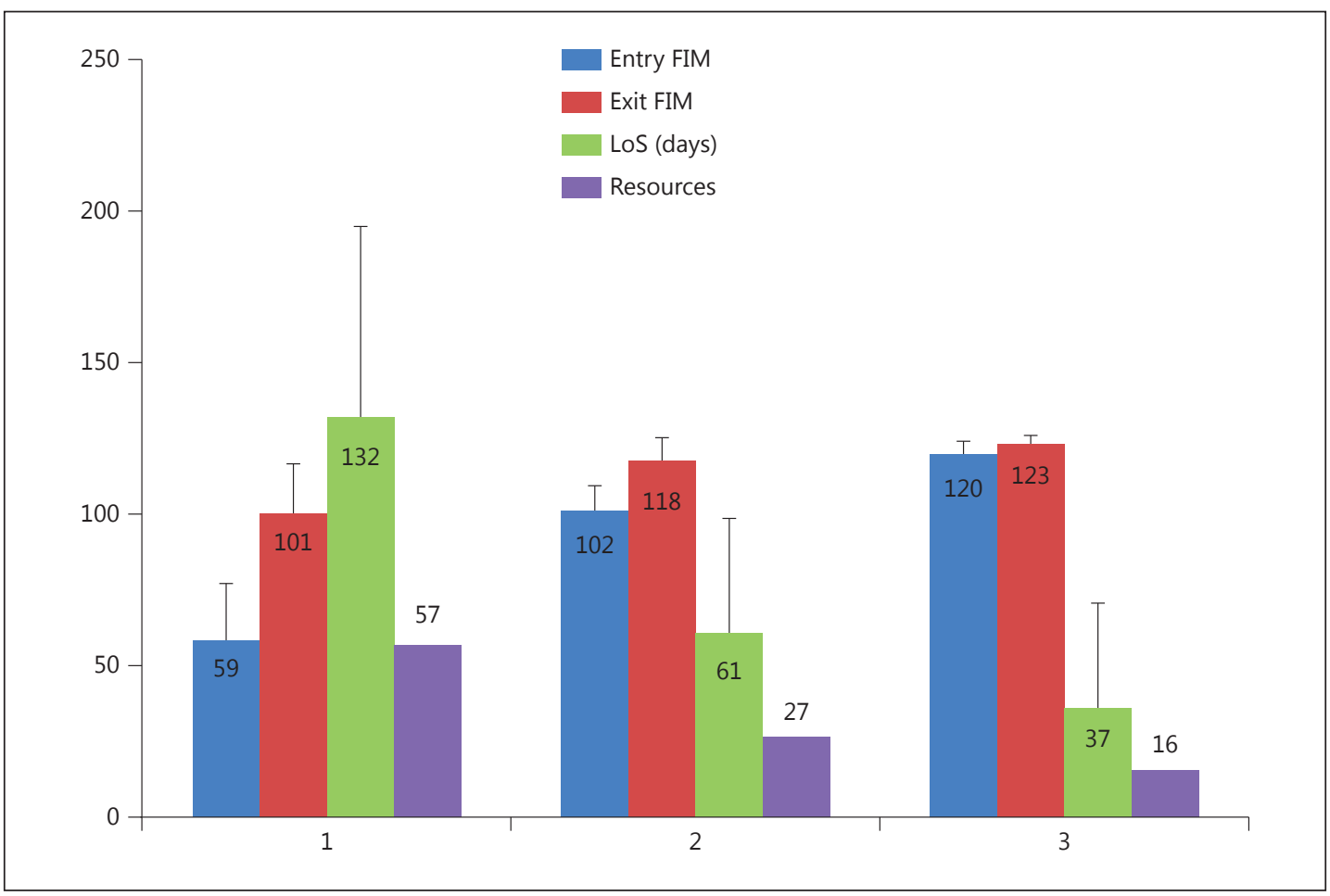

Fig. 1. Stratification of the three groups based on the FIM entry score. Bar graph displaying the mean FIM entry scores (blue) and the exit (red) scores, mean LoS (green) and percentage of resources (number of hospital days for one group/number of hospital days for all patients) of the three groups.

Male gender $(p=0.011)$, having an entry FIM score of $>100(p=0.000)$, LoS of $>70$ days $(p=0.004)$ and relative point gain/week of $>10 \%(p=0.001)$ were identified as positive independent predictors. Age of $>55$ years $(p=0.024)$, aphasia $(p=0.010)$, unilateral spatial neglect $(p=0.013)$, spasticity $(p=0.035)$ and complications $(p=0.003)$ are all negative independent predictors. Stroke type, depression, pain and OAI of $>14$ days do not seem to be independent predictors and have $\mathrm{p}$ values of $>0.05$. Looking at the odd ratios, two variables stand out: the relative possible FIM gain/week of $>10 \%$ that reflects the recovery velocity and the entry FIM of $>100$. Moreover, these two items can be rapidly assessed during early rehabilitation. LoS of $>70$ days was also proven to be a positive predictor.

Then, we stratified the patients according to their FIM entry score into three equivalent groups and calculated the mean entry and exit scores for each group, mean LoS and percentage of total resource allocations (total number of rehabilitation days for a group/total number of rehabilitation days for all patients). The results are shown in figure 1. 


\section{Discussion}

The purpose of the study was to point out some of the predicting factors of a possible discharge home, independently of any social and familial surrounding and of an estimation of the recovery potential of each patient during the early stages of neurorehabilitation.

According to our data, the severity of the stroke, reflected by an FIM entry score of $<100$, is a crucial determinant in predicting a patient's potential of reaching a FIM exit score of $>115$. Then, the velocity of the recovery (relative FIM gain/week $>10 \%$ ) is the second most significant individual predictor that has been revealed in this study. This is an important predictor, which can be rapidly assessed after only few weeks of rehabilitation. $\operatorname{LoS}>70$ days leads to a higher probability to reach the FIM exit mark of 115 . This result has to be assessed in an efficiency point of view. Indeed, a significant improvement in the functional FIM score can be achieved with a long stay; in contrast, it implies a substantial increase in costs. This last point is presented in figure 1 . By stratifying the patients into three equivalent groups according to their FIM entry score, we showed that group 1 (lower FIM entry score) needed more than half of the total resources with only a very limited chance of reaching a FIM exit score and allowing a home discharge without familial and social assistance.

Age, gender, aphasia and unilateral spatial neglect have been described in the literature as negative individual predictors in functional recovery after severe stroke in a general population $[8,9,17]$. Our results confirm these findings in a selected and younger population. However, the type of stroke, which is also described as a significant predictor of recovery in the literature [18], seems to have no significant influence in our population. This can be explained by the age selection of our population, since hemorrhagic strokes occur more often in older patients.

In the present study, complication events and the presence of spasticity were considered to be both negative predicting factors of functional recovery. Therefore, special care should be taken for better prevention and treatment of these two factors in the future.

\section{Conclusion}

Based on these results, the items shown to be of a significant predictive value should be considered and lead to the question of the resource allocation. They could be used to guide rehabilitation centers to better select the patients on admission and during the early phase of the rehabilitation program. Moreover, itshould eventually lead to a new patient management system in which each patient could benefit of a personalized support regarding his individual needs. Given the fact that this study concerns a selected younger population, these findings should be considered carefully regarding the general stroke patient population. Nevertheless, young stroke patients represent a non-negligible and growing proportion, especially with regard to the social burden of stroke disease.

\section{Acknowledgments}

The authors thank Miss Sabrina Panchaud for technical assistance.

\section{Disclosure Statement}

D.H., A.R. and S.C. have nothing to disclose. A.C. has received grant support from the Swiss National Science Foundation. 


\section{References}

1 Murray CJ, Lopez AD: Global mortality, disability, and the contribution of risk factors: Global Burden of Disease Study. Lancet 1997;349:1436-1442.

2 Jorgensen HS, Nakayama H, Raaschou HO, Vive-Larsen J, Stoier M, Olsen TS: Outcome and time course of recovery in stroke. Part I: outcome. The Copenhagen Stroke Study. Arch Phys Med Rehabil 1995;76:399-405.

-3 Payne KA, Huybrechts KF, Caro JJ, Craig Green TJ, Klittich WS: Long term cost-of-ilness in stroke: an international review. Pharmacoeconomics 2002;20:813-825.

$\checkmark 4$ Kissela BM, Khoury JC, Alwell K, Moomaw CJ, Woo D, Adeoye O, et al: Age at stroke: temporal trends in stroke incidence in a large, biracial population. Neurology 2012;79:1781-1787.

5 Kwakkel G, Wagenaar RC, Koelman TW, Lankhorst GJ, Koetsier JC: Effects of intensity of rehabilitation after stroke. A research synthesis. Stroke 1997;28:1550-1556.

6 Kwakkel G, Wagenaar RC, Kollen BJ, Lankhorst GJ: Predicting disability in stroke - a critical review of the literature. Age Ageing 1996;25:479-489.

7 Jorgensen HS, Nakayama H, Raaschou HO, Vive-Larsen J, Stoier M, Olsen TS: Outcome and time course of recovery in stroke. Part II: time course of recovery. The Copenhagen Stroke Study. Arch Phys Med Rehabil 1995; 76:406-412.

-8 Wade DT, Hewer RL, David RM, Enderby PM: Aphasia after stroke: natural history and associated deficits. J Neurol Neurosurg Psychiatry 1986;49:11-16.

-9 Kalra L, Perez I, Gupta S, Wittink M: The influence of visual neglect on stroke rehabilitation. Stroke 1997;28: 1386-1391.

10 Inouye M, Kishi K, Ikeda Y, Takada M, Katoh J, Iwahashi M, et al: Prediction of functional outcome after stroke rehabilitation. Am J Phys Med Rehabil 2000;79:513-518.

11 Lin JH, Hsieh CL, Lo SK, Hsiao SF, Huang MH: Prediction of functional outcomes in stroke inpatients receiving rehabilitation. J Formos Med Assoc 2003;102:695-700.

12 Stineman MG, Maislin G, Fiedler RC, Granger CV: A prediction model for functional recovery in stroke. Stroke 1997;28:550-556.

13 Ween JE, Alexander MP, D'Esposito M, Roberts M: Factors predictive of stroke outcome in a rehabilitation setting. Neurology 1996;47:388-392.

14 De Wit L, Putman K, Schuback B, Komárek A, Angst F, Baert I, et al: Motor and functional recovery after stroke: a comparison of 4 European rehabilitation centers. Stroke 2007;38:2101-2107.

15 Sengler J, Hartmann J, Buisson P, Pierrejean C, Bourderont D: La mesure d'indépendance fonctionnelle (MIF) a-t-elle une valeur prédictive dans les accidents vasculaires cérébraux? Ann Readapt Med Phys 1996;39:553559.

16 Petrea RE, Beiser AS, Seshadri S, Kelly-Hayes M, Kase CS, Wolf PA: Gender differences in stroke incidence and poststroke disability in the Framingham heart study. Stroke 2009;40:1032-1037.

17 Kim JS, Lee KB, Roh H, Ahn MY, Hwang HW: Gender differences in the functional recovery after acute stroke. J Clin Neurol 2010;6:183-188.

18 Paolucci S, Antonucci G, Grasso M, Bragoni M, Coiro P, De Angelis D, et al: Functional outcome of ischemic and hemorrhagic stroke patients after inpatient rehabilitation: a matched comparison. Stroke 2003;34:28612865. 